\title{
Sciendo
}

Research Article

\section{Erasmus University Students Motivation and Segments: The Case of Universitat Politècnica de València, Spain}

\author{
Dr. José-Serafín Clemente-Ricolfe* \\ Paula García-Pinto \\ Universitat Politècnica de València, \\ Valencia, Spain \\ ${ }^{*}$ Corresponding author
}

Doi: 10.2478/jesr-2019-0015

\begin{abstract}
This study quantified Erasmus students' motivations for studying abroad. Surveys were completed by 120 Erasmus students at the Universitat Politècnica de València (UPV) and their motivations for studying abroad were analysed via factor analysis. A two-step cluster analysis was used to segment students' behaviour based on their motivations. Four factors were obtained: individual development, destination choice facilitators, academic aspects and the destination's strong points. Behaviour was not uniform, and two different segments were found. In the first, which we refer to as "without perceived motivations", no motivation was positively rated, while in the second, "with perceived motivations", academics were a key motivating factor. Universities should consider working with the tourism sector to offer activities related to local culture. They could also organise classes outside of school hours to help Erasmus students learn Spanish.
\end{abstract}

Keywords: Erasmus student, motivation, higher education, segmentation

\section{Introduction}

In recent years, students and companies alike have attached great value to the international experience, and a corresponding growth has been seen in the popularity of academic exchange programmes such as that of Erasmus. Many students travel abroad for the purpose of continuing their higher education studies in foreign institutions, a practice that is promoted by exchange schemes, grants and agreements. The mobility of students undertaking a period of study in a foreign university in Europe is on the rise (Ariño, Soler \& Llopis, 2014), with Spain receiving the highest number of Erasmus students, followed by France, Germany and the United Kingdom (Stilianos, Georgios, Vasilik \& Labros, 2013; Böttcher et al., 2016). According to data on Erasmus students published by the European Commission (2015), roughly 290,000 students benefited from European Union grants to study or train abroad in 2015. A 7.4\% increase over the previous year.

The motivating factors behind participation in university exchange programmes have been widely studied in various countries, including the United States, Australia, the United Kingdom and Canada (Wilkins, Balakrishnan \& Huisman, 2012). The experience of living in a foreign country for some length of time is beneficial to students in many regards. For example, improved language skills, knowledge of other cultures and learning with new teaching methods. Universities, however, need to understand the behaviour of such students and, in particular, what motivates them. Although Spain receives a relatively large number of Erasmus university students, we should be learning from those who come here (Valle \& Garrido, 2009). Performing segmentation enables us 
to gain a better understanding by grouping and categorising students with a view to offering them a more satisfactory range of services (Ghosh, Javalgi \&Whipple, 2008).

This paper has two objectives. First, it aims to identify what motivates Erasmus students to study abroad and second, to determine whether Erasmus students can be grouped in terms of their motivations. This study is thus part of a general programme that aims to obtain reliable data on the profiles, needs and expectations of higher education students (Ariño, Soler \& Llopis, 2014), while considering the specific case of Erasmus students at the Universitat Politècnica de València (UPV) in Spain. The main motivations that drive students to undertake Erasmus studies abroad and the methodology of this study are set out in subsequent paragraphs.

\section{Motivations for Erasmus Student Mobility}

From a conceptual point of view, international student mobility could be approached using the pushpull model (Altbach, 1998), that is, the idea that short-term international mobility can be explained by a number of factors that attract (pull) and repel (push) students. On the one hand, there are factors that "push" sudents to leave their home country, given the chance to experience a very different education system. On the other hand, there are also factors that "attract" them to a particular host country, e.g. factors associated with the prestige of the destination university or a positive image of the host country. Push-pull factors, however, are external forces that drive students' behaviour and the choices they make. This approach does not take their individual traits or preferences into account. Nevertheless, students may react to different push-pull factors in different ways. A number of researchers, such as Beerkens, Souto-Otero, Wit \& Huisman (2016), have focused on the basic push-pull model with the aim of developing more sophisticated conceptual models with which to assess the choices made by international students.

There is extensive literature on higher education student exchanges in the European Union. Directories and databases like SpringerLink, Scopus, Google Scholar and Dialnet were thus used to compile the primary motivations for Erasmus students' mobility in the university sphere. The Table 1 shows the results of the compilation. Various earlier studies indicate that learning a language is the most commonly cited reason for Erasmus students' participation in the programme. Fombona, Rodríguez \& Pascual (2013) found that mastering a new language was the motivational factor in $56 \%$ of the answers given by Erasmus students. Aguaded \& Pozo (2009) highlighted that Erasmus students improved their language skills. As one of the students surveyed stated, "In general, my Spanish has improved enormously during my Erasmus study period in Spain, while before I could hardly speak, understand or write it" (p. 333). In other words, the programme makes it easier to learn a foreign language. However, although language acquisition may be a motivating factor for students who feel stimulated and able to try to interact with others in a foreign language, it can also be a barrier due to lack of knowledge and the fear of not being able to communicate in the destination language (Fombona, Rodríguez \& Pascual, 2013).

Table 1. Literature review of the main motives of Erasmus students.

\begin{tabular}{|l|l|}
\hline Motivation & Authors \\
\hline Learning a language & Belvis, Pineda \& Moreno (2007); Pineda, Moreno \& Belvis (2008); Krzaklewska \& Krupnik \\
& (2008); Aguaded \& Pozo (2009); Mures, Huerga, Lanero \& Díaz (2009); Kalocsai (2009); \\
& Jašková \& Heczková (2010); Juvan \& Lesjak (2011); Rodríguez, Bustillo \& Mariel (2011); Aydin \\
& (2012); Bogain (2012); Mitchell (2012); Fombona, Rodríguez \& Pascual (2013); García- \\
& Rodríguez, Kümbül, Jimenez \& Yatağanbaba (2013); Pimentel Botas \& Huisman (2013); \\
& Stilianos et al. (2013); Ariño, Soler \& Llopis (2014); Aslan \& Jacobs (2014); Deakin (2013); \\
& Keresztes (2014); Lesjak, Juvan, Ineson, Yap \& Axelsson (2015); Beerkens et al. (2016); \\
& Brown, Boateng \& Evans (2016); Borghetti \& Beaven (2017); Pedersen, Lopez, Kirikova, \\
\hline Zabłudowski \& Comellas (2017) \\
\hline Seeking new $\begin{array}{l}\text { experiences/personal } \\
\text { development }\end{array}$ & Belvis, Pineda \& Moreno (2007); Pineda, Moreno \& Belvis (2008); Krzaklewska \& Krupnik \\
& (2008); Mures et al. (2009); Jašková \& Heczková (2010); Juvan \& Lesjak (2011); Rodríguez, \\
& Bustillo \& Mariel (2011); Aydin (2012); Bogain (2012); Fombona, Rodríguez \& Pascual (2013); \\
& Pimentel Botas \& Huisman (2013); Stilianos et al. (2013); Ariño, Soler \& Llopis (2014); Aslan \& \\
& Jacobs (2014); Deakin (2013); Keresztes (2014); Currás, Gallarza, Servera, Fayos \& Arteaga \\
& (2015); Lesjak et al. (2015); Asoodar, Atai \& Baten (2017); Pedersen et al. (2017); Sova (2017) \\
\hline
\end{tabular}




\begin{tabular}{|c|c|}
\hline Professional development & $\begin{array}{l}\text { Pineda, Moreno \& Belvis (2008); Krzaklewska \& Krupnik (2008); Jašková \& Heczková (2010); } \\
\text { Juvan \& Lesjak (2011); Aydin (2012); Bogain (2012); Mitchell (2012); Fombona, Rodríguez \& } \\
\text { Pascual (2013); Pimentel Botas \& Huisman (2013); Stilianos et al. (2013); Aslan \& Jacobs } \\
\text { (2014); Deakin (2013); Keresztes (2014); Currás et al. (2015); Lesjak et al. (2015); Pedersen et } \\
\text { al. (2017) }\end{array}$ \\
\hline $\begin{array}{l}\text { Cultural attractiveness of } \\
\text { the destination }\end{array}$ & $\begin{array}{l}\text { Belvis, Pineda \& Moreno (2007); Pineda, Moreno \& Belvis (2008); Mures et al. (2009); Aydin } \\
\text { (2012); Mitchell (2012); García-Rodríguez et al. (2013); Stilianos et al. (2013); Aslan \& Jacobs } \\
\text { (2014); Lesjak et al. (2015); Brown, Boateng \& Evans (2016); Pedersen et al. (2017), Sova } \\
\text { (2017) }\end{array}$ \\
\hline Leisure & $\begin{array}{l}\text { Belvis, Pineda \& Moreno (2007); Pineda, Moreno \& Belvis (2008); Krzaklewska \& Krupnik } \\
\text { (2008); Rodríguez, Bustillo \& Mariel (2011); Juvan \& Lesjak (2011); Aydin (2012); García- } \\
\text { Rodríguez et al. (2013); Aslan \& Jacobs (2014); Lesjak et al. (2015); Sin, Tavares \& Neave } \\
\text { (2017) }\end{array}$ \\
\hline $\begin{array}{l}\text { Personal } \\
\text { recommendations (family, } \\
\text { friends, etc.) }\end{array}$ & $\begin{array}{l}\text { Belvis, Pineda \& Moreno (2007); Pineda, Moreno \& Belvis (2008); Mures et al. (2009); Juvan \& } \\
\text { Lesjak (2011); Aydin (2012); Keresztes (2014); Currás et al. (2015); Brown, Boateng \& Evans } \\
\text { (2016) }\end{array}$ \\
\hline $\begin{array}{l}\text { Economic le } \\
\text { host country } \\
\text { price }\end{array}$ & $\begin{array}{l}\text { Belvis, Pineda \& Moreno (2007); Rodríguez, Bustillo \& Mariel (2011); García-Rodríguez et al. } \\
\text { (2013); Deakin (2013); Keresztes (2014); Lesjak et al. (2015); Beerkens et al. (2016); Cairns } \\
\text { (2017) }\end{array}$ \\
\hline Geographical proximity & $\begin{array}{l}\text { Belvis, Pineda \& Moreno (2007); Pineda, Moreno \& Belvis (2008); Mures et al. (2009); } \\
\text { Rodríguez, Bustillo \& Mariel (2011); Pimentel Botas \& Huisman (2013); Lesjak et al. (2015); Sin, } \\
\text { Tavares \& Neave (2017) }\end{array}$ \\
\hline $\begin{array}{l}\text { Experiencing a new } \\
\text { education system }\end{array}$ & $\begin{array}{l}\text { Krzaklewska \& Krupnik (2008); Mures et al. (2009); Pimentel Botas \& Huisman (2013); Stilianos } \\
\text { et al. (2013); Aslan \& Jacobs (2014); Lesjak et al. (2015) }\end{array}$ \\
\hline $\begin{array}{l}\text { Improving academic } \\
\text { record }\end{array}$ & $\begin{array}{l}\text { Belvis, Pineda \& Moreno (2007); Pineda, Moreno \& Belvis (2008); Krzaklewska \& Krupnik } \\
\text { (2008); Fombona, Rodríguez \& Pascual (2013); Aslan \& Jacobs (2014); Lesjak et al. (2015); } \\
\text { Pedersen et al. (2017) }\end{array}$ \\
\hline $\begin{array}{l}\text { Prestige/academic quality } \\
\text { of the host institution }\end{array}$ & $\begin{array}{l}\text { Mures et al. (2009); Rodríguez, Bustillo \& Mariel (2011); Fombona, Rodríguez \& Pascual (2013); } \\
\text { Pimentel Botas \& Huisman (2013); Stilianos et al. (2013); Keresztes (2014); Cairns (2017) }\end{array}$ \\
\hline $\begin{array}{l}\text { Range of subjects for } \\
\text { study }\end{array}$ & $\begin{array}{l}\text { Belvis, Pineda \& Moreno (2007); Pineda, Moreno \& Belvis (2008); Mures et al. (2009); Juvan \& } \\
\text { Lesjak (2011); Stilianos et al. (2013); Beerkens et al. (2016) }\end{array}$ \\
\hline $\begin{array}{l}\text { Admission/access } \\
\text { requirements }\end{array}$ & $\begin{array}{l}\text { Belvis, Pineda \& Moreno (2007); Pineda, Moreno \& Belvis (2008); Aydin (2012); Fombona, } \\
\text { Rodríguez \& Pascual (2013); Beerkens et al. (2016); Brown, Boateng \& Evans (2016) }\end{array}$ \\
\hline Weather & $\begin{array}{l}\text { Belvis, Pineda \& Moreno (2007); Pineda, Moreno \& Belvis (2008); Rodríguez, Bustillo \& Mariel } \\
\text { (2011); Aydin (2012); Sin, Tavares \& Neave (2017) }\end{array}$ \\
\hline Improving CV & Belvis, Pineda \& Moreno (2007); Jašková \& Heczková (2010); Stilianos et al. (2013) \\
\hline
\end{tabular}

In any event, the Erasmus experience is regarded as being as much a time of learning as a contributing factor in students' personal development (Stilianos et al., 2013). Deakin (2013) highlights two reasons for this: the freedom and independence that students enjoy and their desire to develop personal skills such as self-confidence. In other words, they feel more self-assured and believe they can do anything (Pimentel Botas \& Huisman, 2013). For example, in the study conducted by Krzaklewska \& Krupnik (2008, p. 10), a student described the Erasmus experience as "useful for testing my limits as a person when I'm alone in some kind of difficult situation in a foreign country". In this respect, more than $97 \%$ of international students see the exchange programme as very or extremely important for their personal development (Rodríguez, Bustillo \& Mariel, 2011), and many of them regard personal development as the most influential aspect in their overall assessment of the exchange programme (Mures et al., 2009).

Professional development is another motivating factor amongst Erasmus students. Employers prefer university graduates with international experience, as they have lived in different cultures and been exposed to different working practices (Pimentel Botas \& Huisman, 2013). Our results suggest that studying abroad makes students' CVs more interesting and considerably increases their chance of being considered during the recruitment process. Deakin (2013) points out that comments made by Erasmus students reflect a view that education is first and foremost a path to employment, and that they must therefore acquire a set of skills and credentials that are attractive to prospective employers. According to Aydin (2012), students who participate in the programme gain professional experience, which opens up employment opportunities in their home country (Turkey, in Aydin's study) and abroad.

Students who travel abroad often have favourable experiences with the local culture in their host countries and have the chance to mingle with young people in the host societies (Mitchell, 2012). The importance of this aspect is highlighted in the study by Lesjak et al. (2015), where it 
ranks third among the motivations that drive Erasmus students.

Rodríguez, Bustillo \& Mariel (2011) believe that there is some empirical evidence to support the notion that exchange students are motivated by factors connected with leisure or holiday time. Such a motivation is easy to understand, as students seek leisure as an escape from their study routine, in addition to being a way to gain new experiences.

Friends and university peers offer advice have a major influence on registration in exchange programmes. Family influence is also important, as it can encourage or deter participation in these programmes, although it may not be a decisive factor in the decision (Pineda, Moreno \& Belvis, 2008).

Other motivations relate to the particular characteristics of the destination, such as geographical proximity, the country's economic level and its climate. The university's location, for example, is a motivating factor, as students choose destinations which can help them achieve their specific mobility aims (Pineda, Moreno \& Belvis, 2008). Distance is thus inversely related to student mobility (Rodríguez, Bustillo \& Mariel, 2011). Studies have also found that there is a positive inclination towards Mediterranean countries, where the weather is better (Rodríguez, Bustillo \& Mariel, 2011). Keresztes (2014) mentions that some Erasmus students make their decision based on the relatively low cost of living in a particular country.

Lastly, there is a set of motivations connected with academic factors: experiencing a new system, improving one's academic record, the academic prestige of the destination university, the range of subjects offered, etc. Krzaklewska \& Krupnik (2008, p. 10), for example, cite a statement by an Erasmus student which reflects the academic enrichment entailed by adapting to new educational system: "I see a very different educational system, one that l'd like to work in at some point in the future". Some Erasmus students expect this sort of study programme to improve their academic records due to the impression that Erasmus students are shown tolerance and leeway when marks are assigned (Belvis, Pineda \& Moreno, 2007).

The reasons given by Erasmus students for their international mobility can thus be explained using the push-pull framework. In terms of socio-psychological and intrinsic push factors, the most common are personal and professional development, together with improving their CVs or their academic records. In fact, these push factors are the most frequently cited in the literature (Wilkins, Balakrishnan \& Huisman, 2012). The decision of which host country to choose for an Erasmus exchange depends on a large number of pull factors. Climate, geographical proximity, economic level, attractiveness from a tourism and leisure perspective and language are all factors that attract Erasmus students to a host destination. However, other factors also come into play, such as the host university's prestige and admission requirements as well as the range of subjects offered. Erasmus student mobility pull factors are linked to characteristics of the destination, such as its geographical proximity, as well as to the academic and institutional characteristics of the host university. With a view to the first objective of this paper, it is thus hypothesised that Erasmus students' motivations can be grouped using the push-pull framework.

In summary, and as pointed out by Lesjak et al. (2015), a variety of motivations drive Erasmus students to undertake a period of study at a foreign university. It might be argued that they are motivated to take part in the Erasmus programme by the chance to develop personal, professional and educational skills, as well as by the destination itself (climate, cost, etc.).

Moreover, it should be highlighted that the primary motivations of Erasmus students identified in this study point to an interrelationship between the different variables. The desire to learn a language, for example, is a strong motivation for integration in the host society, but learning a language is also a way for students to improve their employment prospects (Bogain, 2012). The apparent inclination towards Mediterranean countries can be explained by their good weather, which allows easier access to leisure activities for students on the programme (Rodríguez, Bustillo \& Mariel, 2011). Significant correlations have also been found between professional motivations like improving employability and social motivations like enjoying new experiences (Juvan \& Lesjak, 2011). Belvis, Pineda \& Moreno (2007) highlight the major influence that the combined effect of cultural and leisure factors in Spain has on international Erasmus students. In the light of the foregoing, and with a view to the first specific aim of this article, it is hypothesised that the motivations for Erasmus students' mobility are interrelated and could be grouped into different types.

Lastly, it can also be highlighted that Erasmus students' motivations are not uniform across the 
board. Krzaklewska \& Krupnik (2008) found a large gap between Erasmus students in western and central Europe in terms of family circumstances, financial concerns and even in terms of motivation. The authors identified two groups of Erasmus students with different profiles: career-oriented and experience-oriented students. The first group was motivated by academic, employment or language factors, while the second was motivated by factors like having new experiences, leisure or learning about a new culture. It is more common for students with their professional career in mind to be from more disadvantaged family backgrounds (lower family income), to be women and to be from Eastern Europe. The hypothesis posed, with a view to the second objective of this paper, is that there are groups or segments of Erasmus students with different motivations.

\section{Methodology}

\subsection{Participants and Procedure}

The study sample consisted of Erasmus students hosted by the Universitat Politècnica de València (UPV) at its Vera Campus in the city of Valencia during the 2014-2015 academic year. This university was chosen for the study because it is one of the top five universities in Spain in terms of the number of Erasmus students it receives (European Commission, 2015). Moreover, in relative terms, the UPV was the university with the highest average Erasmus participation in the 2000-2008 period (Mures et al., 2009), and in specific terms, it should be noted that internationalisation is an element in the UPV's strategic plan. Information was obtained by means of a personal survey answered by 120 students from the various Schools of Engineering and other faculties offering degree studies at the campus.

In terms of the profile of the Erasmus students surveyed, $53.3 \%$ were male, with an average age of 23.4 and $78.3 \%$ studying an engineering degree, $61.7 \%$ staying for a semester and $27.5 \%$ and $23.3 \%$ from France and Germany, respectively. In terms of their demographic characteristics, and as recommended by Lesjak et al. (2015) for future studies, a good balance between males and females was obtained in the sample, in contrast to other studies in which females are predominant. The average age and the finding that European students remain in Spain for one semester coincides with other studies like those of Mures et al. (2009) or Ariño, Soler \& Llopis (2014).

The choice of a survey as a source of information is justified by previous use of this method in studies on international student mobility (Wilkins, Balakrishnan \& Huisman, 2012). In addition, since the students' decision to study abroad depends on push and pull factors, in both the home and the destination countries ( $\mathrm{Li}$ and Bray, 2007), using the survey method enables Erasmus students to make their views known. For example, they can evaluate whether academic conditions are more or less favourable than those in their home countries. Lastly, in the educational sphere there is a growing use of surveys for analytical purposes, ranging from studying the connections and associations between variables to comparing subgroups in the same population (Alaminos \& Castejón, 2006). Both of these purposes are in line with the aims of this research study. Stratified random sampling with proportional allocation by School or Faculty was used. As Mures et al. (2009) note, some degree programmes, such as business studies, display greater mobility. Similarly, Böttcher et al. (2016) note that participation in the Erasmus programme differs between students of humanities, social science, economics and law and students of subjects relating to engineering, industry and construction. Survey respondents were selected using a systematic sampling method. The first individual was chosen at random and the rest systematically (questioning the first of every two Erasmus students found, and disregarding the second). Fieldwork was carried out by the paper's authors via personal survey (face-to-face) using a structured questionnaire

\subsection{Survey}

The motivations examined in the survey (specifications are provided in Table 2) were compiled based on the studies cited in the literature review above. Erasmus students were asked to evaluate these motivations with the aim of ascertaining the extent to which push-pull factors had influenced them in their choice of the UPV. Since the survey was based on a review of the literature, it can be 
affirmed that its content encompassed the relevant aspects of the topic being studied, that is, the questions were appropriate. The survey was carried out in two languages, English and Spanish, to make it accessible to the greatest possible number of Erasmus students. The replies were graded on a Likert scale, where 1 was "completely disagree", 4 was "neither agree nor disagree", and 7 was "completely agree". Appendix 1 contains the survey that was originally distributed to students.

Table 2. Survey technical specification.

\begin{tabular}{|l|}
\hline $\begin{array}{l}\text { Universe: Erasmus academic exchange students hosted by the Universitat Politècnica de València } \\
\text { (UPV) at the Vera Campus in the } 2014-2015 \text { academic year }\end{array}$ \\
\hline Survey method: Personal interview \\
\hline Sample size: 120 interviews \\
\hline Sample error: $\pm 8.7 \%$ with a confidence level of $95.5 \%(\mathrm{~K}=2)$ \\
\hline Sampling procedure: Randomly stratified sample with proportional allocation by School or Faculty. \\
\hline Fieldwork: December 2014, March, April and May 2015 \\
\hline Prior questionnaire: Test for 21 students \\
\hline
\end{tabular}

\subsection{Data Analysis}

A factor analysis with varimax rotation and Kaiser normalisation (Hair, Anderson, Tatham \& Black 1999) was used to analyse the different types of Erasmus student motivations. This technique analyses the structure of the relationships between a large number of variables, such as the motivations behind international mobility. It is used to describe a set of observable variables (motivations) by means of a smaller number of non-observable or latent (underlying) variables called factors, arranged into groups containing several factors each. Factor analysis provided factor scores at the individual level, while a two-step cluster analysis was used to differentiate participants at the group level. Two-step cluster analysis was used because, unlike traditional agglomeration techniques, it employs an automatic procedure to find the optimal number of clusters. Cluster analysis is comparable to factor analysis in terms of its objective of evaluating students' motivations, but it differs in that it groups individuals together, whereas factor analysis focuses mainly on grouping variables that measure motivations by identifying underlying structures. In summary, the use of both analytical techniques enabled us to explore the data collected to achieve the objectives of this paper. Both analyses were conducted using the SPSS 16.0 program.

\section{Analysis and Discussion of Results}

The paper's first objective was to identify Erasmus students' motives. Factor analysis of Erasmus students' motives resulted in four factors that explained $68.4 \%$ of the variance, with a KMO index of 0.844 (Table 4). Both of these values are indicative of a good overall fit (Hair et al., 1999). Cronbach's alpha coefficient was used to measure reliability, understood as internal consistency. That is, it evaluates how closely related an instrument's set of items are, ranging from 0 to 1 (greater reliability). These values can thus be regarded as suitable for the purpose of exploring the types of motivations that drive Erasmus student mobility in the context of the Universitat Politècnica de València (UPV) in Spain. The factors that were identified are interpreted below. To this end, the discussion uses factor weightings which are simply correlations between each variable and the factor in question, meaning that the higher the weighting, the stronger the connection between the variable and the factor.

The first factor encompasses three motivations associated with improved professional or personal development. It could thus be labelled an "individual development" factor. Professional aspects are combined with aspects relating to the individual's personal growth. Erasmus students seem to perceive that the experience has positive effects on their future as people, and it could be said that they feel free to - or indeed, have a duty to improve their CVs or their professional or personal lives. Moreover, this same aspect is in line with findings widely described in the literature (Messer \& Wolter, 2007; Aslan \& Jacobs, 2014; Lesjak et al., 2015). 
Table 3. Factor analysis of the motivations of Erasmus students in the UPV (rotated factor loadings)

\begin{tabular}{|c|c|c|c|c|}
\hline Motivations/Factors & 1 & 2 & 3 & 4 \\
\hline Improve CV & 0.872 & & & \\
\hline Improve my professional future & 0.807 & & & \\
\hline Facilitate my professional development & 0.758 & & & \\
\hline City's tourism attractiveness (natural resources, culture, history) & & 0.833 & & \\
\hline Geographical proximity to home university & & 0.729 & & \\
\hline Ease of admission process & & 0.544 & & \\
\hline Recommendations and good feedback & & 0.530 & & \\
\hline Leisure & & 0.412 & & \\
\hline Prestige of the UPV & & & 0.789 & \\
\hline High quality of studies & & & 0.711 & \\
\hline Learning Spanish & & & & 0.773 \\
\hline Good weather & & & & 0.717 \\
\hline Low cost of living & & & & 0.518 \\
\hline$\%$ explained variance & 39.7 & 12.2 & 9.2 & 7.3 \\
\hline Cronbach's alpha & 0.895 & 0.769 & 0.726 & 0.559 \\
\hline $\begin{array}{l}\text { Name of the factors: } \\
\text { Factor 1: individual development } \\
\text { Factor 2: destination choice facilitators } \\
\text { Factor 3: academic aspects } \\
\text { Factor 4: the destination's strong points }\end{array}$ & & & & \\
\hline
\end{tabular}

The second factor comprises motivations like the city's appeal as a tourist destination, its geographical proximity, easy admission processes, recommendations and favourable feedback, and leisure. This factor could thus be described as "destination choice facilitators", because it encompasses aspects that make the process simpler or more attractive for the Erasmus student. The opposite also occurs, as shown by feedback from an Erasmus student in the study by Aslan \& Jacobs (2014, p. 70): "I came up against a lot of bureaucratic problems and this reduced my motivation".

The third factor relates to the UPV's prestige and high academic standard. This factor could thus be called "academic aspects". The increased quality of study programmes offered by host universities for mobile students should be taken into account (Pineda, Moreno \& Belvis (2008). However, with respect to students' learning process, it should be noted that the studies they undertake at such universities also offer a certain flexibility in terms of exams, the option of working as part of a team or being able to choose from a range of elective subjects (Aslan \& Jacobs, 2014). All of the above appears to be even more pronounced when the higher education institution attended by the Erasmus students has a considerable reputation.

Lastly, the fourth factor encompasses learning the Spanish language, good weather and a low cost of living. In other words, "the destination's strong points". As Rodríguez, Bustillo \& Mariel (2011) point out, some aspects of the host country make it more attractive compared to other potential destinations. This factor also highlights the international importance of the Spanish language today. It is the official language in 21 countries, and the third most widely-spoken language in the world (Valle \& Garrido, 2009).

With respect to the paper's second objective, Erasmus students were segmented using the factorial scores obtained earlier as grouping variables. Handling the data in this way results in uncorrelated variables. The unit of measurement is the same for all of the variables analysed and the number of variables is not too great. The "non-hierarchical" grouping technique known as KMean was chosen because a hierarchical technique with a set of data for more than 50 individuals is difficult to represent and interpret. It should be noted that the K-Means method is generally regarded as the most robust method available in the SPSS statistical package (Punj \& Stewart, 1983). The use of non-hierarchical methods is also advisable when the aim is not so much to analyse the hierarchical structure of the individuals as to ascertain the number of groups that exist and the characteristics of each one. The aim was to segment Erasmus students in the UPV according to their motivations, grouping them into different dimensions. The corresponding calculations produced two groups, which made more sense in terms of interpreting the results (Table 4). The Euclidean distance was used in this paper. 
Table 4. Segmentation of Erasmus students in the UPV by motivations and segment characterisation

\begin{tabular}{|c|c|c|}
\hline & $\begin{array}{c}\text { Segment } 1 \\
\text { "without perceived motives' }\end{array}$ & $\begin{array}{c}\text { Segment } 2 \\
\text { "with perceived motives' }\end{array}$ \\
\hline & $\begin{array}{c}(\mathrm{n}=64) \\
(53.3 \%)\end{array}$ & $\begin{array}{c}(\mathrm{n}=56) \\
(46.7 \%)\end{array}$ \\
\hline \multicolumn{3}{|l|}{ Segmentation variables } \\
\hline Individual development * & -0.20 & 0.22 \\
\hline Facilitators in choice of destination * & -0.21 & 0.24 \\
\hline Academic aspects ** & -0.55 & 0.63 \\
\hline Destination strong points ** & -0.39 & 0.44 \\
\hline \multicolumn{3}{|l|}{ Segment characterisation } \\
\hline Age (average) & 23.2 & 23.5 \\
\hline \multicolumn{3}{|l|}{ Sex $(\%)$} \\
\hline Male & 60.9 & 44.6 \\
\hline Female & 39.1 & 55.4 \\
\hline \multicolumn{3}{|l|}{ Nationality (\%) * } \\
\hline Germany & 26.6 & 19.6 \\
\hline France & 26.6 & 28.6 \\
\hline Italy & 10.9 & 25.0 \\
\hline Eastern Europe & 12.5 & 19.6 \\
\hline Rest of Europe & 23.4 & 7.1 \\
\hline \multicolumn{3}{|l|}{ Period in the UPV $(\%)$ * } \\
\hline One semester & 71.9 & 50.0 \\
\hline Full academic year & 28.1 & 50.0 \\
\hline \multicolumn{3}{|l|}{ Type of studies (\%) } \\
\hline Engineering & 79.7 & 76.8 \\
\hline$A D E / F i n e ~ A r t s$ & 20.3 & 23.2 \\
\hline Score for services offered by the UPV ** & 3.8 & 4.2 \\
\hline
\end{tabular}

The first group, which represents a little over half of the students surveyed, is characterised by its negative scoring of the various motivations. This segment could therefore be labelled as "without perceived motivations", as its members assign a negative rating to the various factors into which the motivations are grouped. This finding coincides with that of Stilianos et al. (2013), who noted that some students said they obtained no significant benefits from their participation in the Erasmus programme. The second group, on the other hand, representing $46.7 \%$ of the sample, rated the various motivations positively, emphasising in particular the academic aspects of their Erasmus study period. This segment could be called "with perceived motivations". In both segments, the pull factor that we labelled "academic aspects" was rated the highest, while the push motivations encompassed within the "individual development" factor received the lowest score. This result is in line with the conclusions drawn by Wilkins \& Huisman (2011), who found that push factors had a minimal influence; it was pull factors that had the greatest bearing on the choice of country and university. In an increasingly global environment with a growing number of national and international universities, motivations associated with academics and with the host destination are possibly more important.

Use of the push-pull model has improved our understanding of the Erasmus student experience, but the various motivations underlying students' behaviour must not be overlooked and an attempt should be made to link them to students' particular characteristics: their nationality, the length of their stay, etc. In terms of the features of the two segments, the group labelled "without perceived motivations" includes a greater percentage of students from Germany and other prosperous European countries (the Netherlands, Belgium, the UK, etc.) than the segment "with perceived motivations", which includes a greater proportion of Erasmus students from Italy and Eastern Europe. This result may seem at odds with the findings of Beerkens et al. (2016), who conclude that there are few differences between countries. However, Rodríguez, Bustillo \& Mariel (2011) argue that the motivations that drive Erasmus students to study abroad depend on the region where their home country is located, with differences arising based on their respective levels of development. This research study also found that the segment "with perceived motivations" contains a higher percentage of students who remain for the entire academic year $(50 \%$, compared to $28.1 \%$ in the segment 
"without perceived motivations"). This may be explained by the fact that the longer they spend away from their home university, the greater they perceive the benefit to be (Messer \& Wolter, 2007). Segmentation appears to show that nationality may be linked to a need for change or to disappointment with the situation in the student's home country (pushing), while length of stay may be tied to allowing enough time to try another education model (pulling). Internationalisation could pose a threat to countries with more push than pull, such as those with a poor standard of English language, low salaries or less prestigious universities. It also has a positive side, however, as it improves students' ability to adapt to circumstances in a short period of time.

Lastly, Erasmus students from the segment "with perceived motivations" gave a higher score to services offered by the UPV (on a scale of 1 to 5 , where 5 was "very good"). Jašková \& Heczková (2010) found that students who perceived greater benefits felt more satisfied with the services offered. However, closer examination of the causal link between motivations and scoring of university services is warranted, with a view to exploring the hypothesis that unmotivated students may have felt as they did because of poor services (library, language centre, etc.).

\section{Conclusions}

Erasmus students' motivations were reduced to four factors through factor analysis. Two of them, "destination choice facilitators" and "the destination's strong points", are pull forces which essentially consist of the characteristics of the host destination. The factor which we call "academic aspects" also encompasses pull motivations, although these relate to academic preferences. The existence of two factors which encompass motivations associated with the host destination might be explained by the growing number of universities to choose from (Wilkins \& Huisman, 2011). It could be hypothesised that very unacademic factors seem to have great weight in an Erasmus student's decision.

Social and psychological or intrinsic push factors as well as pull factors influence students' choice of destination. University managers should consider the possible relationships between these factors. During students' mandated study periods, it may thus be advisable to offer them opportunities for both professional development, such as short company placements, and personal development, such as a chance to practice their Spanish outside of class. At the same time, this would also help increase their enjoyment of their period of study away from home. For example, universities could work with tourism professionals to develop products that would enable students to explore local culture while having fun. In this regard, it may be worth considering the development of flats or halls of residence for Erasmus students in Valencia's old quarter, a neighbourhood that's centrally located but has deteriorated to a certain extent in some areas. This could stimulate the local economy and the nightlife sector (Malet, 2013). Furthermore, since the other university in the city of Valencia, the Universitat de València, is also one of the universities that receives the most Erasmus students, the two could work together. For example, they could jointly communicate the features of the destination that make it attractive to these sorts of students.

In terms of segmentation, our findings reveal two diametrically opposed groups of Erasmus students: one that has been labelled "without perceived motivations" and one labelled "with perceived motivations". In view of this, university management staff who encounter students that match the profiles of the segment with perceived motivations could aim to increase the effectiveness of their communication by tailoring messages to suit their specific needs. In addition, research techniques such as group dynamics could be used to carry out an in-depth investigation of the reasons for the negative ratings assigned by the group "without perceived motivations", although one initial hypothesis might be that the Erasmus students in this segment may be motivated by the desire to develop their European identity with this period abroad (Sigalas, 2010).

The results obtained in this study offer two significant contributions. First, although the literature has focused extensively on student mobility there is a dearth of research into the motivations of Erasmus students (Rodríguez, Bustillo \& Mariel, 2011), which is why this study aims to make a quantitative contribution towards improving our understanding of them, revealing the multifaceted nature of the Erasmus experience. Second, methods that have been used to study international student mobility in the past have been primarily interview-based. In contrast, this study used surveys with a statistical sampling, ensuring the representativeness of the sample. In summary, this study 
makes a valuable contribution in terms of broadening knowledge and understanding of the motivations behind Erasmus students' international mobility, supported by previous research studies which have relied mainly on qualitative research. In closing, however, it should be noted that this study does have a major limitation. The university studied, the Universitat Politècnica de València (UPV), is located in a coastal area with a large number of historic and cultural attractions. It would be advisable, therefore, to analyse whether the results obtained differ in institutions with a different set of cultural and geographical features.

\section{References}

Aguaded, J. L. \& Pozo, C. (2009). Los alumnos Erasmus en la Torre de Babel. El aprendizaje de lenguas extranjeras basado en las competencias comunicativas y en el uso de las TIC. Revista Electrónica Teoría de la Educación. Educación y Cultura en la Sociedad de la Información, 10(2), 310-337.

Alaminos, A., \& Castejón, J. L. (2006). Elaboración, análisis e interpretación de encuestas, cuestionarios y escalas de opinión. Alicante: Marfil.

Altbach, P. G. (1998). Comparative higher education: Knowledge, the university, and development. Hong Kong: Comparative Education Research Centre, The University of Hong Kong.

Ariño, A., Soler, I. \& LLopis, R. (2014). La movilidad estudiantil universitaria en España. RASE: Revista de la Asociación de Sociología de la Educación, 7(1), 143-167.

Aslan, B. \& Jacobs, D. B. (2014). Erasmus Student Mobility: Some Good Practices According to Views of Ankara University Exchange Students. Journal of Education and Future, (5), 57-72.

Asoodar, M., Atai, M. R., \& Baten, L. (2017). Successful erasmus experience: Analysing perceptions before, during and after erasmus. Journal of Research in International Education, 16(1), 80-97. doi:10.1177/1475240917704331

Aydin, S. (2012). I am not the same after my ERASMUS: A Qualitative Research. The Qualitative Report, 17(28), 1-23.

Belvis, E., Pineda, P. \& Moreno, M. V. (2007). La participación de los estudiantes universitarios en programas de movilidad: factores y motivos que la determinan. Revista Iberoamericana de Educación, 42(5), 1-1.

Beerkens, M, Souto-Otero, M., de Wit, H. \& Huisman, J. (2016). Similar students and different countries? An analysis of the barriers and drivers for Erasmus participation in seven countries. Journal of Studies in International Education, 20(2), 184-204. doi:10.1177/1028315315595703

Bogain, A. (2012). Erasmus language students in a British university: a case study. The Language Learning Journal, 40(3), 359-374. doi:10.1080/09571736.2012.723937

Borghetti, C.,\& Beaven, A. (2017). Lingua francas and learning mobility: Reflections on students' attitudes and beliefs towards language learning and use. International Journal of Applied Linguistics (United Kingdom), 27(1), $221-241$. doi:10.1111/ijal.12123

Böttcher L., Araújo N. A. M., Nagler J., Mendes J. F. F., Helbing D.,\& Herrmann H. J. (2016). Gender Gap in the ERASMUS Mobility Program. PLoS ONE, 11(2), e0149514. doi:10.1371/journal.pone.0149514.

Brown, M., Boateng, E. A., \& Evans, C. (2016). Should I stay or should I go? A systematic review of factors that influence healthcare students' decisions around study abroad programmes. Nurse Education Today, 39, 63-71. doi:10.1016/j.nedt.2015.12.024

Cairns, D. (2017). The erasmus undergraduate exchange programme: A highly qualified success story? Children's Geographies, 15(6), 728-740. doi:10.1080/14733285.2017.1328485

Currás, R., Gallarza, M. G., Servera, D., Fayos, T. \& Arteaga, F. (2015). The consumer value trade-off and the international experience: benefits and costs of being an Erasmus student. INTED2015 Proceedings, 2nd-4th March, Madrid, pp. 4008-4017.

Deakin, H. (2013). The drivers to Erasmus work placement mobility for UK students. Children's Geographies, 12(1), 25-39. doi:10.1080/14733285.2013.851063

European Commission (2015). Erasmus+ Programme Annual Report 2015. https://ec.europa.eu/programmes /erasmusplus/sites/erasmusplus/files/erasmus-plus-annual-report-2015.pdf. Accessed 20 March 2017.

Fombona, J., Rodríguez, C. \& Pascual, M. Á. (2013). The motivational factor of Erasmus students at the university. International Education Studies, 6(4), doi:10.5539/ies.v6n4p1.

García-Rodríguez, F., Kümbül, T., Jimenez, J. M. \& Yatağanbaba, E. (2013). A whole world outside home: factors attracting Erasmus students and their effects on intercultural competence, language learning, economy and tourism. EDULEARN13 Proceedings, 3726-3734.

Ghosh, A. K., Javalgi, R. \&Whipple, T. W. (2008). Service strategies for higher educational institutions based on student segmentation. Journal of Marketing for Higher Education, 17(2), 238-255. doi:10.1080/08841240801912641

Hair, J. F.; Anderson, R. E.; Tatham, R. L.; \& Black, W. C. (1999). Análisis Multivariante. Madrid. Prentice-Hall.

Jašková M. \& Heczková L. (2010). Erasmus Mobility: Students Motivation and Satisfaction. ERACON Congress 1-5 July 2010, University of Vienna.

Juvan, E. \& Lesjak, M. (2011). Erasmus Exchange Program: Opportunity for professional growth or sponsored vacations? Journal of Hospitality \& Tourism Education, 23(2), 23-29. doi:10.1080/10963758.2011.10697003

Kalocsai, K. (2009). Erasmus exchange students: A behind-the-scenes view into an ELF community of practice. ApplesJournal of Applied Language Studies, 3(1), 24-48.

Keresztes, E. R. (2014). The analysis of foreign study in higher education in the perspective of Hungarian exchange students. Polish Journal of Management Studies, 9, 96-103. 
Krzaklewska, E. \& Krupnik, S. (2008). The Role of the Erasmus Programme in Enhancing Intercultural Dialogue. Presentation of the Results from the Erasmus Student Network Survey 2007. Proceedings of the 4th International Barcelona Conference on Higher Education, Vol. 6. Higher education for intercultural dialogue and multiculturalism. Barcelona: GUNI.

Lesjak, M., Juvan, E., Ineson, E. M., Yap, M. H. T. \& Axelsson, E. P. (2015). Erasmus student motivation: Why and where to go?. Higher Education, 70(5), 845-865. doi:10.1007/s10734-015-9871-0

Li, M., \& Bray, M. (2007). Cross-border flows of students for higher education: Push-pull factors and motivations of mainland Chinese students in Hong Kong and Macau. Higher Education, 53(6), 791-818. doi:10.1007/s10734-005-5423-3

Malet, D. (2013). Procesos de revalorización patrimonial en el barrio de Alfama: el papel de los estudiantes Erasmus en la tematización de la ciudad. Etnográfica, 17(1), 31-50.

Messer, D. \& Wolter, S. C. (2007). Are student exchange programs worth it?. Higher Education, 54(5), 647-663. doi:10.1007/s10734-006-9016-6

Mitchell, K. (2012). Student mobility and European Identity: Erasmus Study as a civic experience?. Journal of Contemporary European Research, 8 (4), 490-518.

Mures Quintana, M. J., Huerga Castro, C., Lanero Fernández, J. J. \& Díaz Martínez, M. (2009). El programa Erasmus en los estudios económico-empresariales: análisis y valoración. Pecvnia, 9, 129-156. doi:10.18002/pec.v0i9.665

Pedersen, J. M., Lopez, J. M. G., Kirikova, M., Zabłudowski, Ł., \& Comellas, J. (2017). Motivations and outcomes: A study of an intensive international course. International Journal of Engineering Education, 33(3), 1086-1097.

Pimentel Botas, P. C. \& Huisman, J. (2013). A Bourdieusian analysis of the participation of Polish students in the ERASMUS programme: cultural and social capital perspectives. Higher Education, 66(6), 741-754. doi:10.1007/s10734-013-9635-7

Pineda, P., Moreno, M. V. \& Belvis, E. (2008). La movilidad de los universitarios en España: estudio sobre la participación en los programas Erasmus y Sicue. Revista de Educación, 346, 0157-159.

Punj, G. \& Stewart, D. W. (1983). Cluster analysis in marketing research. Review and suggestions for application. Journal of Marketing Research, 20(2), 134-148. doi:10.2307/3151680

Rodríguez, C., Bustillo, R. \& Mariel, P. (2011). The determinants of international student mobility flows: an empirical study on the Erasmus programme. Higher Education, 62(4), 413-430. doi:10.1007/s10734-010-9396-5

Sin, C., Tavares, O., \& Neave, G. (2017). Student mobility in portugal: Grappling with adversity. Journal of Studies in International Education, 21(2), 120-135. doi:10.1177/1028315316669814

Sigalas, E. (2010). Cross-border mobility and European identity: The effectiveness of intergroup contact during the ERASMUS year abroad. European Union Politics, 11(2), 241-265.

Sova, R. B. (2017). Understanding erasmus students' motivation: What directs erasmus students' choice of destination and particular course. New Educational Review, 50(4), 26-35. doi:10.15804/tner.2017.50.4.02

Stilianos, P., Georgios, A., Vasilik, K. \& Labros, S. (2013). The Erasmus Student Mobility Program and Its Contribution to Multicultural Education: The Case of Tecnological Education Institute of Thessaly. Journal of Educational and Social Research, 3(3), 181-200. doi:10.5901/jesr.2013.v4n3p181

Valle, J.M. \& Garrido, R. (2009). La asimetría en los flujos de movilidad de estudiantes Erasmus. Revista Española de Educación Comparada, 15, 93-130.

Wilkins, S., \& Huisman, J. (2011). International student destination choice: the influence of home campus experience on the decision to consider branch campuses. Journal of Marketing for Higher Education, 21(1), 61-83. doi:10.1080/08841241.2011.573592

Wilkins, S., Balakrishnan, M. S., \& Huisman, J. (2012). Student choice in higher education: Motivations for choosing to study at an international branch campus. Journal of Studies in International Education, 16(5), 413-433. doi:10.1177/1028315311429002

Appendix 1: Original text of the question about the motives of Erasmus students at the UPV.

In terms of the motives that prompted you to choose the UPV as your host university, please could you tell me how much you agree with the following statements? Interviewer: read and hand over the reply card with $1=$ "Completely disagree" to $7=$ "Completely agree".

$\square$ Prestige of the UPV

$\square$ Ease of admission process

$\square$ High quality of studies

$\square$ Learning Spanish

$\square$ Good weather

$\square$ Low cost of living

$\square$ Recommendations and good feedback

$\square$ Geographical proximity to home university

$\square$ City's tourism attractiveness (natural resources, culture, history)

$\square$ Leisure

$\square$ Facilitate my professional development

$\square$ Improve my CV

$\square$ Improve my professional future 